\title{
Sistem Manajemen Pembelajaran Lokal untuk Meningkatkan Pemahaman Belajar Mahasiswa
}

\author{
http://dx.doi.org/10.28932/jutisi.v6i1.1818
}

\author{
Fridolin F. Paiki ${ }^{\bowtie 1}$, Alex De Kweldju ${ }^{\# 2}$, Ratna Juita ${ }^{\# 3}$ \\ \#Jurusan Teknik Informatika, Universitas Papua, Amban, Manokwari \\ ${ }^{1}$ ff.paiki@unipa.ac.id \\ ${ }^{2} a \cdot d e k w e l d j u @ u n i p a \cdot a c \cdot i d$ \\ ${ }^{3}$ r.juita@unipa.ac.id
}

\begin{abstract}
The Learning Management System (LMS) is one of the important tools used in schools and campuses to improve students abilities in learning. The availability of web servers and computer networks that are fast, reliable, inexpensive, easily accessible and integrated with the LMS can help students to keep up with the lectures. The objectives of this research are to implement a learning management system, to measure its performance, and to study its impact on improving students' academic performance in a particular lecture. Web server for LMS is implemented using a virtual machine (VM) Proxmox. Web server quality is measured using Apache Bench and the Web Server Stress Tool. The students are divided into two classes, namely experimental classes and control classes. Their study results are measured using pre-test and post-test. T-test was used to measure the significance of improvement. The simulation results using Apache Bench obtained that the time required to complete 1,000 concurrent requests is 13,823 milliseconds. Although it is not optimal, the results are close to ideal conditions, which is less than 10 seconds. The study results improved significantly based on t-test, especially on experimental class, with P-value 0.00000466. The server is implemented virtually so that it can be easily deployed to other local servers in other faculties. The results show that server performance still needs to be improved, considering the needs of students and lecturers will increase in the future. Network quality also needs to be considered, such as the use of firewalls, antiviruses, and other applications that can affect the quality of responses received by users. Basic networking infrastructure needed to be improved in order to provide better experiences. Diversification of learning media also needs to be used so that research results can also cover different conditions and protocols.
\end{abstract}

Keywords - Control Class; Experimental Class; Learning Management System; Moodle; Stress Test.

\section{Pendahuluan}

\section{A. Latar Belakang}

Cukup tingginya kebutuhan dan aktivitas mahasiswa UNIPA, khusus program studi S1 Teknik Informatika dalam menggunakan komputer dan internet telah menuntut tersedianya jaringan komputer dan internet yang baik. Di samping itu, saat ini aktivitas online mahasiswa cenderung bersifat acak dalam hal penggunaan aplikasi internet untuk melakukan kegiatan yang berhubungan dengan perkuliahan. Hal ini menyebabkan adanya kebutuhan akses internet yang lebih besar tetapi tidak efektif dan tidak terukur pengaruhnya terhadap pemahaman materi perkuliahan.

Kekompleksan jaringan komputer UNIPA dan banyaknya kendala teknis adalah hal-hal yang mungkin menyebabkan ketidakstabilan koneksi internet dan server web UNIPA pada umumnya. Oleh karena itu, peneliti berkeinginan untuk membangun server web yang bersifat lokal dengan menggunakan komputer dengan spesifikasi standar, yang lebih sederhana dalam manajemen tetapi diharapkan mampu menjawab kebutuhan mahasiswa akan kegiatan online yang cepat, murah, dan handal. Penggunaan Sistem Manajemen Pembelajaran atau Learning Management System (LMS) yang ditempatkan pada server web lokal, diharapkan mampu mengorganisasi kegiatan online mahasiswa, mengurangi kebutuhan akses internet, dan meningkatkan pemahaman siswa terhadap materi perkuliahan. Aplikasi Moodle (Modular Object-Oriented Dynamic Learning Environment) akan digunakan sebagai aplikasi LMS dalam penelitian ini.

Teknologi virtualisasi yang ada saat ini juga memungkinkan untuk mengimplementasikan sistem yang sama pada beberapa tempat/lokasi penyimpanan. Selain itu, kapasitas komputer host yang digunakan pun bisa dikelola 
sedemikian rupa menyesuaikan dengan kebutuhan pada setiap lokasi.

Penelitian ini akan dilakukan di laboratorium komputer S1 Teknik Informatika UNIPA dan akan melibatkan mahasiswa S1 Teknik Informatika sebagai responden. Pengukuran akan dilakukan pada pengukuran trafik dan kestabilan akses ke server web lokal dan peningkatan pemahaman belajar mahasiswa dengan memanfaatkan server web lokal dan Moodle.

\section{B. Tujuan}

Penelitian ini bertujuan untuk:

1. Menyediakan alternatif teknologi server web yang dapat dipasang pada jaringan kecil di tiap fakultas.

2. Menyediakan rekomendasi model server web dan LMS ke UPT Pusat Komputer untuk dipasang dalam skala universitas.

3. Memberikan akses kepada mahasiswa ke server web dan aplikasi didalamnya dengan gratis, cepat dan handal.

4. Mengorganisasi kegiatan online mahasiswa yang terkait perkuliahan melalui Moodle yang dapat dipasang pada server web lokal sehingga mengurangi frekuensi penggunaan internet yang kurang bermanfaat.

\section{Ruang Lingkup}

Ruang lingkup dari penelitian ini adalah:

a. Penyiapan server, baik perangkat keras maupun perangkat lunaknya.

b. Instalasi Moodle sebagai LMS yang akan digunakan.

c. Pengukuran kinerja server menggunakan Apache Bench dan Web Server Stress Tool.

d. Pengukuran prestasi dan kemampuan mahasiswa setelah kegiatan perkuliahan selesai.

\section{TINJAUAN PUSTAKA}

\section{A. Server Web}

Kebutuhan akan internet semakin meningkat dari hari ke hari seiring dengan meningkatnya jumlah pengguna dan isi (content) yang terdapat di internet. Meningkatnya jumlah pengguna berakibat pada makin tingginya permintaan per detik ke server web yang akan meningkatkan beban kerja server web dan meningkatkan lalu lintas data dari dan ke server. H. Ensour dan A. Kayed telah melakukan pengujian dengan menggunakan Web server Stress Tool untuk menguji kinerja server web [1]. Mereka berkesimpulan bahwa lalu lintas data yang terlalu tinggi pada server web akan menyebabkan kemacetan (bottleneck) yang mengganggu kinerja server web. Penelitian sebelumnya, M. Arlitt dan C. Williamson juga mengungkapkan fakta bahwa ketika bottleneck terjadi, utilisasi CPU akan mencapai $100 \%$ menunjukkan kinerja maksimal dari CPU [2]. Kondisi 100\% ini akan mengurangi kemampuan server web untuk merespon semua permintaan dari klien yang juga mengurangi kecepatan transfer.

J. Nielsen berpendapat bahwa waktu tunggu menggunakan internet adalah sangat penting bagi pengguna [3]. Fokus mereka akan terus terjaga pada waktu tunggu < 0.1 detik. Waktu tunggu > 10 detik akan membuat mereka mudah teralihkan ke kegiatan yang lain dan menjadi kehilangan ketertarikan pada apa yang sedang dikerjakan. Seperti yang dikemukakan oleh penelitian sebelumnya yang dilakukan oleh E. Hernández-Orallo dan J. Vila-Carbó, waktu tunggu ini erat kaitannya dengan kinerja server web [4]. Dengan demikian, pengguna akan lebih fokus dalam melakukan kegiatan online bila server web memberikan layanan yang cepat.

\section{B. Learning Management System}

Learning Management System (LMS) adalah suatu metode pengelolaan kegiatan pembelajaran berbasis sistem informasi. LMS biasa digunakan bagi pembelajaran online, baik yang sifatnya full online maupun yang bersifat blended learning.

LMS telah banyak digunakan oleh berbagai pendidikan tinggi di dunia untuk mendukung proses pembelajaran. T. J. McGill dan J. E. Klobas mengemukakan bahwa banyak universitas telah berinvestasi dan menggunakan LMS sebagai salah satu sumber daya teknologi informasi untuk mendukung pendidikan online baik di dalam maupun di luar kampus [5]. D. Weaver, C. Spratt, dan C. S. Nair mengindikasi adanya pertumbuhan yang besar dalam hal pemanfaatan LMS di pendidikan tinggi, yang mana telah memberikan lingkungan pembelajaran yang lebih kaya bagi mahasiswa, baik yang belajar di dalam kampus maupun yang mengikuti pembelajaran jarak jauh [6]. C. M. Mehrotra, C. D. Hollister, and L. McGahey menyatakan bahwa pendidikan jarak jauh bukanlah upaya masa depan bagi universitas, tetapi lebih merupakan suatu kenyataan yang menuju kepada penciptaan peluang baru yang melampaui batas fisik kampus untuk menjangkau pasar mahasiswa global [7].

Moodle adalah salah satu aplikasi Sistem Manajemen Pembelajaran yang bersifat gratis dan open source (kode program dapat dilihat dan diubah). Moodle dapat memfasilitasi pustaka dari kelas (kuliah, artikel, pengumuman) dan juga aktivitas pembelajaran (tugas, 
diskusi, kuis, wiki). Selain itu, Moodle memiliki fitur nilai yang akan menghitung nilai siswa secara otomatis. Berbagai format presentasi material didukung oleh Moodle, seperti Flash, Html, Adobe Presentation, gambar, suara, dan video yang membuat Moodle menjadi sarana yang menarik dan interaktif. Penggunaan Moodle di Indonesia hingga September 2012 tercatat 1.075 situs dan didominasi oleh sekolah menengah atas. Di lingkungan universitas, Moodle digunakan baik oleh universitas negeri maupun swasta, seperti ITB, UGM, UI, UPI, Amikom, Atmajaya, Binus, dan lain-lain. Aplikasi ini dapat menjadi alat belajar alternatif yang mempromosikan proses pembelajaran yang lebih menarik dan efisien di lingkungan perguruan tinggi [8].

D. R. Garrison and H. Kanuka mengatakan bahwa penggunaan teknologi dan kegiatan online dalam pembelajaran bagi mahasiswa perguruan tinggi merupakan strategi yang baik dengan resiko rendah untuk membantu mahasiswa menghadapi tantangan perkembangan teknologi terkini [9]. Mereka menemukan adanya hubungan antara mahasiswa yang belajar dengan melibatkan pola pikir tinggi dengan metode pembelajaran yang melibatkan teknologi online. Temuan ini mengkonfirmasi hasil dari penelitian sebelumnya oleh K. Precel, Y. Eshet-Alkalai [10], M. V. López-Pérez, M. C. Pérez-López, and L. Rodríguez-Ariza [11].

\section{Performance Measurement}

Ketersediaan dan kinerja dari suatu layanan merupakan faktor penting dalam layanan berbasis IT. Kedua faktor ini sangat berpengaruh terhadap tingkat kepuasan pengguna layanan tersebut. Hasil penelitian menunjukkan bahwa dalam layanan berbasis web, baik website, portal, blog, lamanya waktu tunggu yang diinginkan oleh user minimum sebesar 10 detik. Hal ini tentu saja ditentukan oleh banyak faktor, seperti konektifitas jaringan, spesifikasi server, dan konfigurasi server.

Konektifitas jaringan di sini biasanya ditentukan oleh jenis perangkat keras dan perangkat lunak yang digunakan. Misalnya jenis kabel (UTP Cat5, UTP Cat6, atau Fiber Optic), berkabel atau nirkabel, spesifikasi router.

Untuk mengukur kinerja sistem, baik dari sisi kinerja perangkat keras maupun perangkat lunak yang digunakan, terdapat banyak sekali perangkat yang bisa digunakan, baik yang gratis, open source, hingga yang berbayar, seperti yang dikemukakan oleh Cordel Vail [12]. Di dalam dokumen tersebut terdapat berbagai informasi terkait perangkatperangkat yang bisa digunakan untuk mengukur kinerja suatu sistem.

\section{Metode Penelitian}

\section{A. Lokasi dan Partisipan}

Perancangan dan pembangunan server web akan dilakukan di Laboratorium Pemrograman 1 Program Studi S1 Teknik Informatika, Jurusan Teknik, Universitas Papua. Ruang Tugas Akhir akan difungsikan sebagai pusat perancangan, implementasi dan monitoring Moodle. Penelitian ini akan melibatkan 55 mahasiswa S1 Teknik Informatika yang mengontrak mata kuliah Jaringan Komputer II sebagai partisipan. Pemilihan terhadap partisipan dilakukan secara acak dan bersifat sukarela.

\section{B. Perangkat Keras dan Perangkat Lunak}

Pada dasarnya, untuk membangun server web yang handal dibutuhkan komputer server dengan spesifikasi yang handal juga. Akan tetapi dalam penelitian ini peneliti akan menggunakan komputer dengan spesifikasi standar sebagai alternatif teknologi berbiaya rendah. Komputer yang digunakan adalah komputer rakitan - bukan buildup/bermerek - dengan spesifikasi sebagai berikut:

$\begin{array}{lll}\text { a. Prosesor } & \text { : Intel i3 } 3.3 \mathrm{Ghz} \\ \text { b. Memori } & \text { : DDRIII } 2 \mathrm{~Gb} \\ \text { c. Hard Disk } & : 250 \mathrm{~Gb} \\ \text { d. Kartu Grafis } & \text { : onboard } \\ \text { e. DVDRom } & \text { : Lite-on 16x } \\ \text { f. Kartu Jaringan } & \text { : onboard } \\ \text { g. Mouse/Keyboard } & \text { : USB }\end{array}$

Peralatan jaringan komputer (router, switch, wifi dan kabel UTP) dan komputer klien akan memanfaatkan peralatan pada Laboratorium Pemrograman 1. Beberapa modifikasi dan perluasan jaringan akan dilakukan sesuai kebutuhan penelitian.

Perangkat lunak yang digunakan untuk membangun server web adalah sistem operasi berbasis Linux, yaitu Ubuntu 14 Server Edition. Ubuntu dipilih perangkat lunak telah dikenal luas sebagai salah satu sistem operasi server yang handal, aman dan gratis. Aplikasi server lainnya adalah server web (Apache), server database (MySql), bahasa pemrograman server (PHP5) dan firewall (Shorewall). Moodle akan dipasang pada server sebagai aplikasi LMS.

Perangkat lunak pada komputer klien adalah adalah sistem operasi Windows 7 Home Edition dan web browser Chrome. Untuk mengukur kinerja dari server, peneliti akan menggunakan dua aplikasi benchmark, yaitu Apache Bench and Web server Stress Tool. 


\section{Server Web}

Pembangunan server web dimulai dari instalasi sistem operasi Ubuntu 14 Server Edition pada komputer yang didedikasikan sebagai server. Aplikasi server lainnya (Apache, MySql, PHP5, dan Shorewall) akan diinstalkan dan dikonfigurasi setelah Ubuntu terinstal dengan baik. Server ini kemudian akan dihubungkan dengan LAN (Local Area Network) pada Laboratorium Pemrograman 1. Jaringan komputer menggunakan topologi Star, yang melibatkan switch dan wifi. Pada akhir dari penelitian ini, laboratorium komputer lainnya di S1 Teknik Informatika (Laboratorium Pemrograman 2) akan dihubungkan dengan server ini untuk menguji kestabilan dan kemampuan penanganan beberapa jaringan LAN sekaligus.

Pengukuran kinerja server web dilakukan dengan menggunakan 2 aplikasi benchmark, yaitu Apache Bench dan Web server Stress Tool. Apache Bench akan menghitung kemampuan Apache Server untuk menangani permintaan tiap detiknya. Pada Web server Stress Tool, peneliti akan menggunakan 2 parameter dari 6 parameter yang tersedia, yaitu User dan Clicks. Parameter Users digunakan untuk mensimulasikan jumlah pengguna (11000) yang mengakses server. Clicks digunakan untuk menghitung jumlah klik ke alamat internet/URL (Universal Request Locator) tertentu. Dengan menggunakan paramater Clicks, kita akan melihat beban kerja pada alamat tertentu.

Hasil benchmark server web lokal akan dibandingkan dengan benchmark server build-up (IBM) di Laboratorium Jaringan untuk melihat signifikasi perbedaan kinerja, terutama untuk lingkungan fakultas dengan jumlah pengguna 1-1000 pengguna.

Pengukuran kestabilan server web akan dilakukan dengan cara menjalankan server selama 24 jam x 35 hari. Jumlah 35 hari adalah waktu dimana kelas ekperimental akan diadakan dengan memanfaatkan server dan Moodle. Data tentang lalu-lintas data akan dicatat dan dianalisa.

\section{Moodle}

Aplikasi Moodle akan dipasang pada server web yang telah dibuat. Konfigurasi akan dilakukan pada server dan juga Moodle agar dapat diakses dari komputer klien yang menggunakan sistem operasi Windows 7 atau Windows XP. Pengujian akan dilakukan dari komputer klien untuk memastikan seluruh tampilan grafis Moodle dapat ditampilkan dengan baik, demikian juga semua fitur di dalam Moodle. Mahasiswa diluar kelas akan dapat mengakses Moodle pada seluruh jaringan wifi UNIPA menggunakan laptop masing-masing dengan sistem operasi apa saja.
Materi perkuliahan Jaringan Komputer II akan dimodifikasi sebanyak 3 modul sehingga partisipan akan memiliki beberapa kegiatan online yang semuanya dilakukan melalui Moodle. Hal-hal yang akan dilakukan di Moodle antara lain:

a. Membuat link dan halaman khusus untuk kuliah Jaringan Komputer II.

b. Memodifikasi dan menempatkan seluruh modul pelajaran. 3 modul pelajaran dimodifikasi sedemikian rupa agar partisipan memiliki kegiatan online yang menggunakan Moodle.

c. Menempatkan artikel-artikel yang terkait perkuliahan di Moodle agar dapat di unduh (download) partisipan.

d. Menyediakan tempat untuk partisipan mengunggah (upload) tugas.

e. Membuat ruang tanya-jawab antara partisipan dan dosen di tiap modul.

\section{E. Kelas Kontrol dan Kelas Eksperimen}

Seperti yang disampaikan sebelumnya, mata kuliah yang diamati perkembangan studinya adalah Jaringan Komputer II dan terbagi menjadi dua kelas, yaitu kelas kontrol dan kelas eksperimen. Kelas kontrol akan menerima perkuliahan sebagaimana biasanya, sedangkan kelas eksperimen akan menerima perkuliahan yang melibatkan Moodle. Dua dosen akan terlibat dalam menyampaikan materi perkuliahan. Masing-masing dosen akan mengajar pada kelas yang berbeda. Jumlah mahasiswa pada masingmasing kelas adalah 29 mahasiswa pada kelas kontrol dan 26 mahasiswa pada kelas eksperimen. Pokok bahasan yang digunakan dalam pengambilan data pada penelitian ini adalah konsep TCP/IP, IP statis dan dinamis, routing dan subnetting.

Untuk mengukur tingkat pemahan partisipan, dilakukan tes awal dan tes akhir pada kedua kelas untuk melihat apakah ada peningkatan pemahaman pada 3 modul yang dilibatkan dalam penelitian ini. Untuk meningkatkan tingkat kepercayaan (reliability), metode interater akan digunakan yang melibatkan 2 peneliti. Derajat persetujuan (degree of agreement) akan dihitung untuk menunjukan tingkat kepercayaan. Tes awal dan tes akhir yang diberikan akan menggunakan format pertanyaan berupa pilihan ganda dan essay. Dalam hal ini, kelas kontrol akan menggunakan format berbasis kertas (paper-based test), sedangkan kelas eksperimen akan menggunakan Moodle dengan format berbasis komputer (computer-based test).

Tes t-dependen akan digunakan untuk melihat ada tidaknya perbedaan yang signifikasi dari nilai partisipan antara tes awal dan tes akhir. Tes t-independen akan 
digunakan pada nilai tes akhir antara kelas kontrol dan kelas eksperiment untuk melihat siginifikasi perbedaan nilai antara tes awal dan tes akhir.

\section{HASIL DAN PEMBAHASAN}

\section{A. Benchmarking}

Dalam pengukuran benchmarking, ada dua aplikasi yang digunakan, yaitu ApacheBench dan Web Server Stress Tool.

Seperti yang diketahui, Apache Bench berfungsi untuk menghitung kemampuan server dalam mengelola HTTP request yang diterima. Apache Bench diinstall pada server terpisah agar tidak memberikan beban bagi server LMS, namun tetap berada pada jaringan lokal. Proses eksekusinya adalah dengan menjalankan perintah berikut pada Window terminal.

Dalam hal ini, perintah tersebut menjalankan 1000 HTTP request ke alamat http://elearning.unipa.ac.id dengan jumlah request yang dijalankan secara bersamaan adalah 100 request. Halaman web e-learning yang akan diakses dapat dilihat pada Gambar 1 (halaman Home) dan Gambar 2 (halaman Dashboard mata kuliah Jaringan Komputer II). Dari Hasil pengukuran yang diperoleh dari aplikasi Apache Bench dapat dilihat pada Gambar 3 dan Gambar 4.

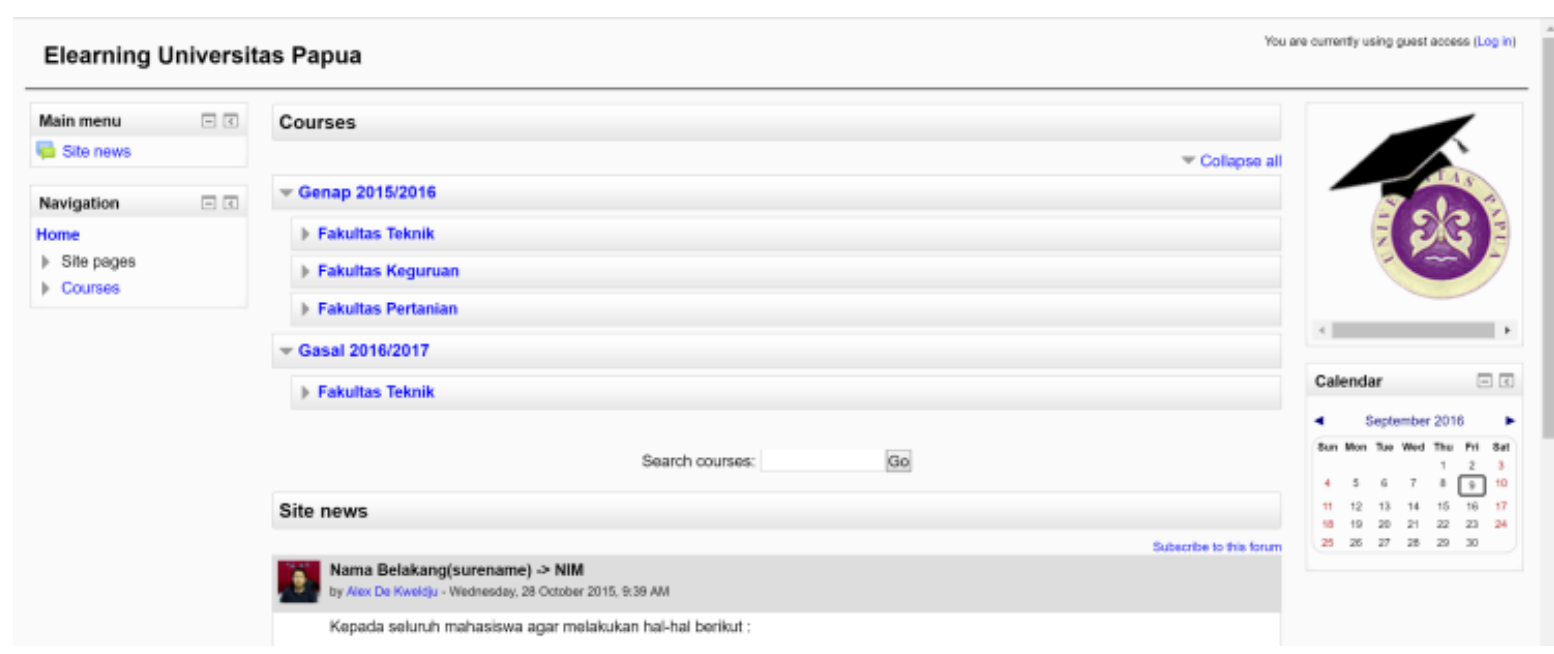

Gambar 1. Tampilan Halaman Home Moodle

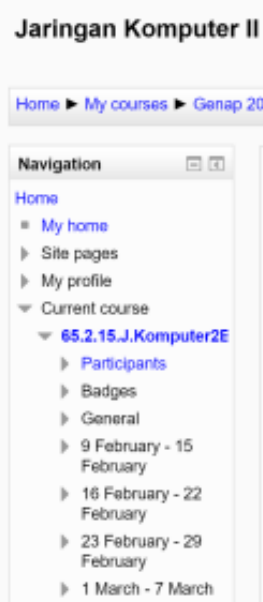

Jaringan Komputer II Kelas B 


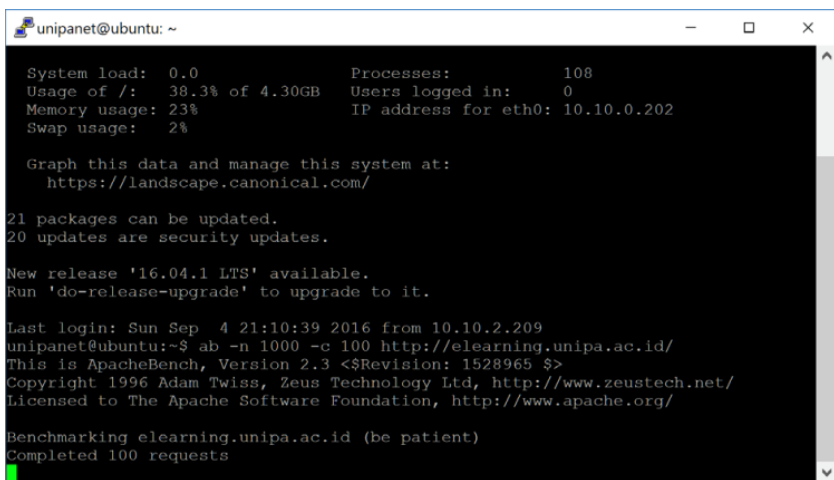

Gambar 3. Proses Apache Bench Dimulai

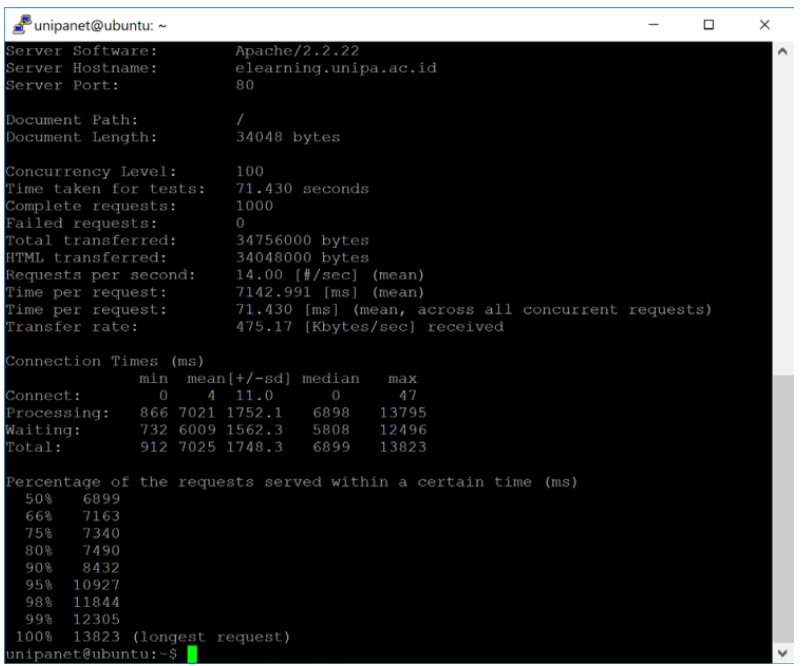

Angka 100 dipilih sebagai jumlah concurrent request karena melihat jumlah mahasiswa terbanyak yang mengambil mata kuliah tertentu adalah 100 mahasiswa sedangkan total 1000 request diambil untuk mensimulasikan jika LMS digunakan oleh 10 kelas pada Jurusan Teknik Informatika pada waktu tertentu.

Data pada Gambar 4 menunjukkan bahwa untuk menyelesaikan 1.000 request, diperlukan waktu sebanyak 13.823 detik. Hal ini sudah mendekati kondisi yang diinginkan dimana waktunya kurang dari 10 detik.

Benchmarking menggunakan Web Server Stress Tool akan mengukur kinerja server dalam hal melihat performa server dalam mengelola beberapa request sekaligus ke berbagai URL yang berbeda.

Dalam penelitian ini, digunakan dua URL, yaitu halaman login (http://elearning.unipa.ac.id/login/index.php) dan halaman

UTS (http://elearning.unipa.ac.id/mod/quiz/view.php?id=702).

Dari tiga mode pengujian yang tersedia, mode yang diambil adalah Time dimana pengujian dilakukan dalam kurun waktu tertentu. Waktu eksekusi adalah selama 1 menit untuk 100 pengguna. Jumlah ini dibuat untuk menyesuaikan dengan data jumlah mahasiswa pada kelas tersebut (seperti pada pengujian Apache Bench). Konfigurasi mode pengujian yang digunakan dapat dilihat pada Gambar 5.

Gambar 4. Proses Apache Bench Selesai

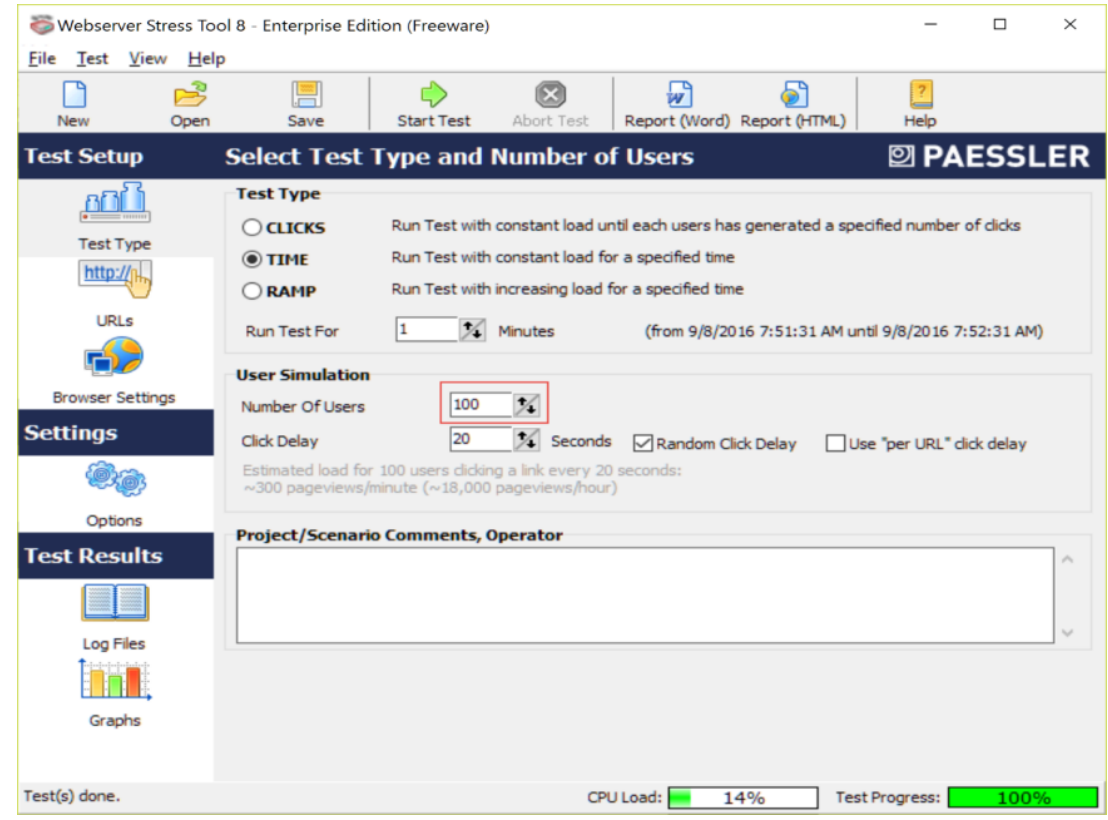

Gambar 5. Konfigurasi Jenis Pengujian 
Pada halaman Login ditambahkan username dan password. Hal ini diperlukan karena tanpa login, pengguna tidak bisa mengakses materi-materi dan aktivitas-aktivitas di dalam LMS. Oleh sebab itu, pada pengujian ini sistem perlu melalui halaman Login terlebih dahulu sebelum masuk ke halaman UTS.

Setelah dijalankan, hasilnya secara real time akan ditampilkan dan secara otomatis, log file-nya akan dibuat oleh Webserver Stress Tool, baik secara keseluruhan (Detailed.log) maupun secara individu (per pengguna). Hasil akhir dari pengujian ini pun dapat ditampilkan dalam bentuk tabel dan grafik seperti yang ditunjukkan pada Tabel I, Gambar 6, Gambar 7 dan Gambar 8.

TABEL I.

DATA PER URL

\begin{tabular}{|l|r|l|l|}
\hline URL & Clicks & $\begin{array}{l}\text { Time } \\
\text { Spent } \\
\text { (ms) }\end{array}$ & $\begin{array}{l}\text { Average } \\
\text { Click } \\
\text { Time } \\
\text { (ms) }\end{array}$ \\
\hline $\begin{array}{l}\text { http://elearning.unipa.ac.id/1 } \\
\text { ogin/index.php }\end{array}$ & 306 & 376.701 & 1.231 \\
\hline$\underline{\text { http://elearning.unipa.ac.id/ }}$ & 255 & 229.693 & 901 \\
\hline
\end{tabular}

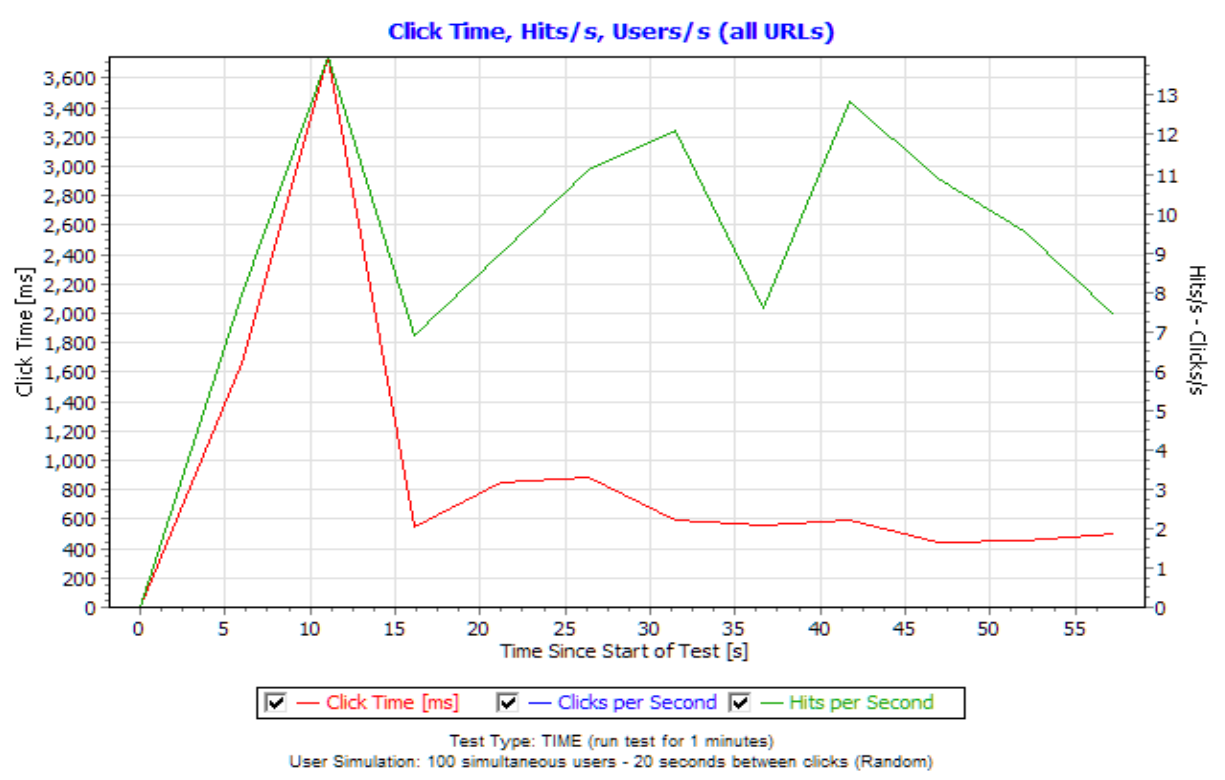

Gambar 6. Click Time dan Hits untuk Semua URL

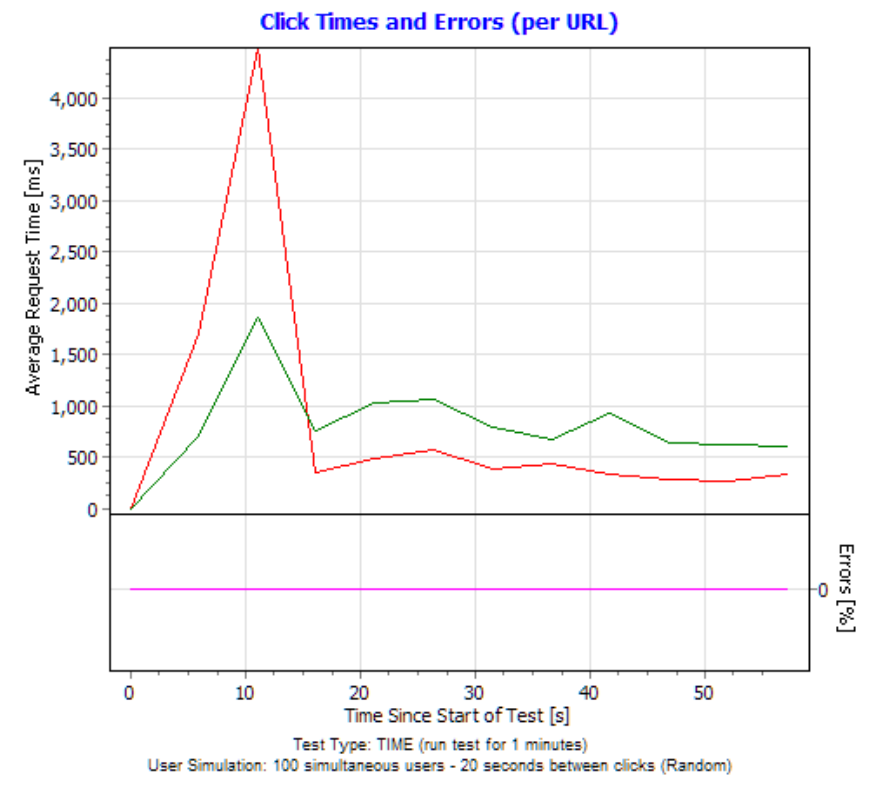

Gambar 7. Click Time dan Hits per URL 


\section{Spectrum of Click Times}

"How many users waited for how long under what load to complete a click?"

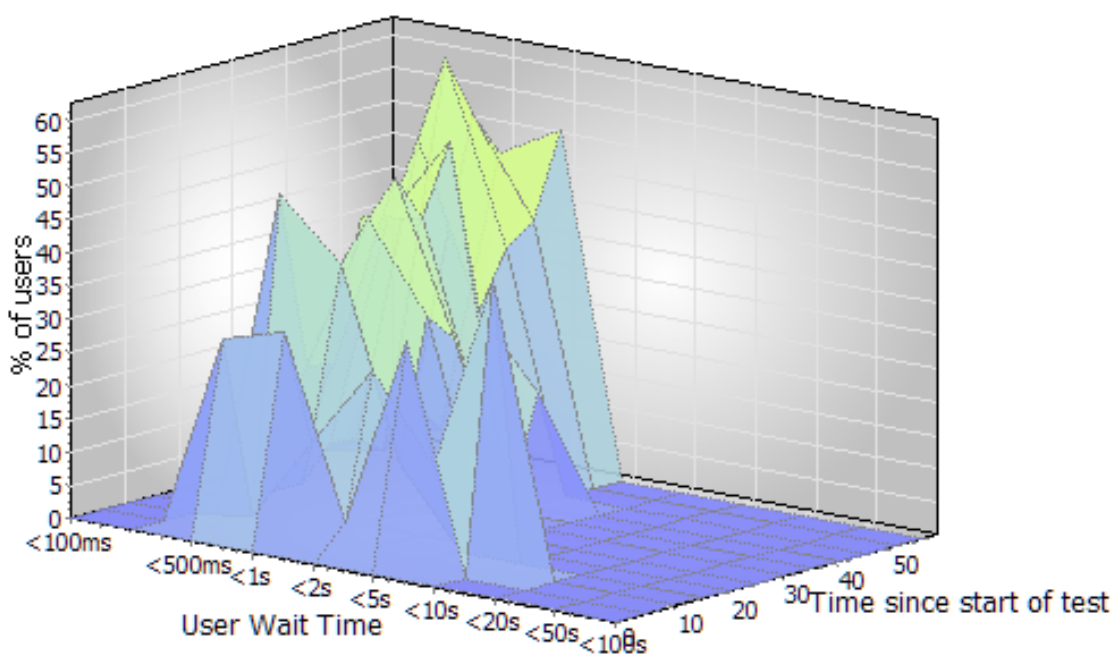

Test Type: TIME (nun test for 1 minutes)

User Simulation: 100 simultaneous users - 20 seconds between clicks (Random)

Gambar 8. Spektrum Klik dan Respon Web

\section{B. Hasil Studi}

Hasil studi dan analisis pengaruh LMS terhadap hasil studi mahasiswa diukur melalui tes awal dan tes akhir. Materi yang dimasukkan ke dalam kedua tes adalah konsep TCP/IP, IP statis dan dinamis, routing, dan subnetting. Tes ini dilakukan pada kelas kontrol dan kelas eksperimen.

Jumlah partisipan adalah sebanyak 55 mahasiswa dengan 29 mahasiswa pada kelas kontrol dan 26 mahasiswa pada kelas eksperimen. Hasil tes awal dan tes akhir yang diperoleh untuk setiap kelas dapat dilihat pada grafik distribusi nilai kedua kelas pada Gambar 9 dan Gambar 10.

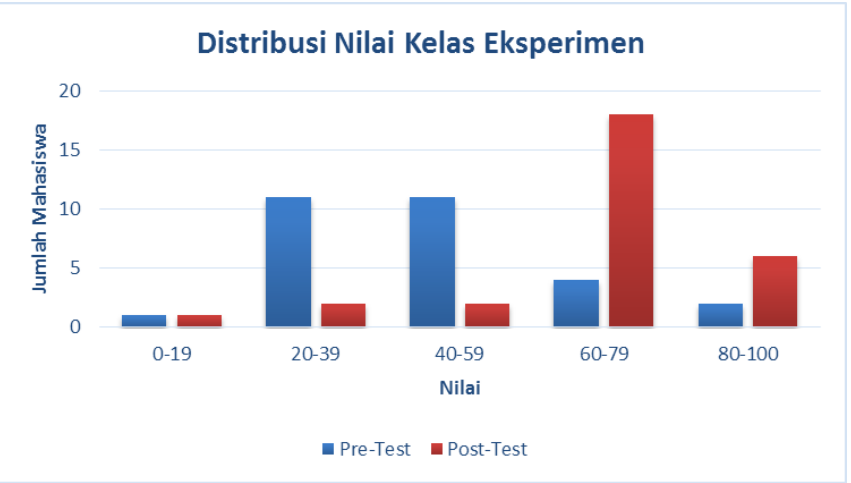

Gambar 9. Distribusi Nilai Kelas Eksperimen

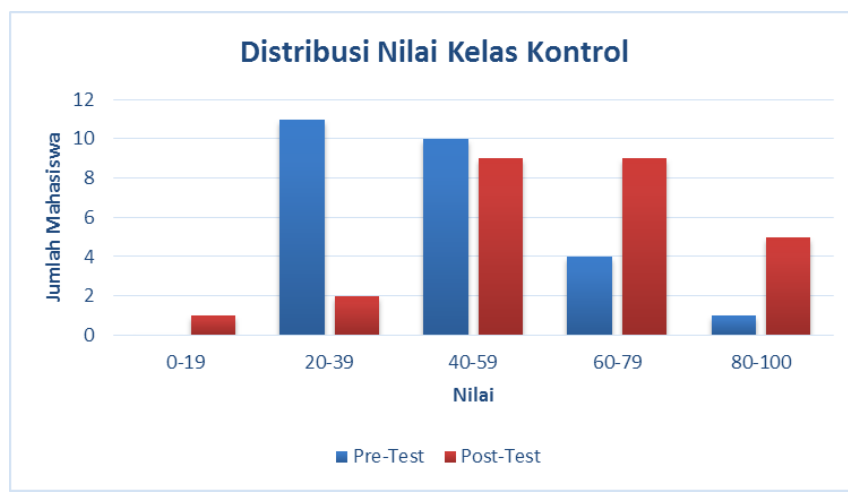

Gambar 10. Distribusi Nilai Kelas Kontrol

Dari Gambar 9 dan Gambar 10, secara sekilas terlihat bahwa pada kelas eksperimen terjadi peningkatan nilai antara nilai tes awal dan nilai tes akhir. Hal ini terlihat bahwa lebih dari $80 \%$ mahasiswa yang memiliki nilai tes awal di bawah 60 kini mengalami peningkatan dimana $80 \%$ mahasiswa tersebut justru memiliki nilai akhir di atas 60 . Meskipun di kelas kontrol pun terjadi peningkatan nilai, namun distribusi mahasiswa dengan nilai di bawah 60 pada tes akhir masih cukup besar. Hal ini terbukti melalui uji t yang dilaksanakan.

Hasil uji t juga menunjukkan terdapat peningkatan yang signifikan dari nilai tes awal ke nilai tes akhir. Meskipun 
pada kedua kelas terdapat peningkatan yang signifikan, dapat dilihat bahwa besarnya perubahan juga lebih signifikan pada kelas eksperimen daripada kelas kontrol. Hasil uji tersebut dapat dilihat pada Tabel II.

TABEL II.

HASIL UJI T

\begin{tabular}{|r|l|}
\hline \multicolumn{2}{|c|}{ Kelas Eksperimen } \\
\hline $\mathrm{n}$ & 29 \\
\hline selang kepercayaan & $95 \%$ \\
\hline $\mathrm{t}$ table & 2.045 \\
\hline $\mathrm{t}$ test & 5.654251098 \\
\hline P value & 0.00000466 \\
\hline Kelas Kontrol \\
\hline $\mathrm{n}$ & 26 \\
\hline $\mathrm{t}$ table & 2.056 \\
\hline $\mathrm{t}$ test & 4.930805 \\
\hline P value & 0.0000446 \\
\hline
\end{tabular}

\section{KESIMPULAN}

Berdasarkan hasil penelitian yang dilakukan dapat diperoleh dua kesimpulan. Kesimpulan yang pertama adalah spesifikasi dari komputer dan virtual server masih perlu ditingkatkan agar dapat memenuhi kinerja server yang baik. Kesimpulan yang kedua adalah pengelolaan jaringan, khususnya pada sisi traffic management, perlu dioptimalkan lagi agar dapat mendukung sepenuhnya request yang dikelola oleh server.

\section{DAFTAR PUSTAKA}

H. Ensour and A. Kayed, "Web server performance evaluations under workloads with different parameters," European Journal of Scientific Research, vol. 22, no. 2, pp. 251-268, 2008.
M. Arlitt and C. Williamson, "Understanding web server configuration issues," Software - Practice and Experience, vol. 34, no. 2, pp. 163-186, Feb. 2004.

[3] J. Nielsen. (2009) Powers of 10: Time scales in user experience. [Online]. Tersedia: https://www.nngroup.com/articles/powers-of10-time-scales-in-ux/.

[4] E. Hernández-Orallo and J. Vila-Carbó, "Web server performance analysis using histogram workload models," Computer Networks, pp. 2727-2739, 2009.

[5] T. J. McGill and J. E. Klobas, "A task-technology fit view of learning management system impact," Computers and Education, vol. 52, no. 2, pp. 496-508, 2009.

[6] D. Weaver, C. Spratt, and C. S. Nair, "Academic and student use of a learning management system: Implications for quality," Australasian Journal of Educational Technology, vol. 24, no. 1, pp. 30-41, 2008.

[7] C. M. Mehrotra, C. D. Hollister, and L. McGahey, Distance Learning: Principles for Effective Design, Delivery, and Evaluation. Sage Publications, 2012.

[8] A. P. Lopes, "Teaching with Moodle in higher education," in INTED2011 Proceedings, 2011, pp. 970-976.

[9] D. R. Garrison and H. Kanuka, "Blended learning: uncovering its transformative potential in higher education," Internet and Higher Education, vol. 7, no. 2, pp. 95-105, 2004.

[10] K. Precel, Y. Eshet-Alkalai, and Y. Alberton, "Pedagogical and design aspects of a blended learning course," The International Review of Research in Open and Distributed Learning, vol. 10, no. 2, pp. 1-15, 2009.

[11] M. V. López-Pérez, M. C. Pérez-López, and L. Rodríguez-Ariza, "Blended learning in higher education: students' perceptions and their relation to outcomes," Computers and Education, vol. 56, no. 3, pp. 818-826, 2011.

[12] C. Vail. (2005) Stress, load, volume, performance, benchmark and base line testing tool evaluation and comparison. [Online]. Tersedia: $\quad$ http://vcaa.com/tools/loadtesttoolevaluationchart023.pdf. 